\title{
Gender differences and chronic obstructive pulmonary disease: an update on the literature
}

\author{
Elena Barbagelata, ${ }^{1}$ Antonello Nicolini, ${ }^{2}$ Immacolata Ambrosino, ${ }^{3}$ Cecilia Politi ${ }^{4}$ \\ ${ }^{1}$ Internal Medicine Department, General Hospital, Sestri Levante (GE); ${ }^{2}$ Respiratory Diseases Unit, General Hospital, Sestri \\ Levante (GE); ${ }^{3}$ ASL Lecce, DSS Maglie (LE); ${ }^{4}$ Department of Internal Medicine, Veneziale Hospital, Isernia, Italy
}

\begin{abstract}
Chronic obstructive pulmonary disease (COPD) has traditionally been viewed as a disease affecting older men with a history of smoking, while being neglected and under-diagnosed in women. This scenario has changed in recent years as there has been a steady increase in COPD prevalence and mortality rates in women. The increased prevalence of COPD among women is likely attributable to several factors including the increased rates of cigarette smoking observed in women during recent years, exposure to indoor air pollution as well as increased occupational exposures since women take on previously male-dominated occupational roles related to risk exposure. In this review we have analyzed the difference in COPD phenotypes and features related to gender difference.
\end{abstract}

\section{Introduction}

A large number of studies report the existence of sex-related (biological, hormonal, genetic) differences and gender-related (environmental, socio-cultural) differences in the manifestations of chronic obstructive pulmonary disease (COPD), including a faster decline in lung function and worse symptoms among females, who also seem to be more susceptible to the toxic effects of cigarette smoke.

The impact of COPD worldwide is expected to increase with a heavy economic burden on individuals and society.

The smoke is the best known etiological factor for this respiratory disease. Reflecting the high prevalence

Correspondence: Antonello Nicolini, Respiratory Diseases Unit, General Hospital, via Terzi 43, 16039 Sestri Levante (GE), Italy.

Tel.: +39.0185329145. E-mail: antonellonicolini@gmail.com

Key words: Chronic obstructive pulmonary disease; gender difference; smoking exposure; comorbidities; exacerbations.

Conflict of interest: the authors declare no potential conflict of interest.

Received for publication: 5 February 2018.

Revision received: 9 May 2018.

Accepted for publication: 1 June 2018.

This work is licensed under a Creative Commons Attribution NonCommercial 4.0 License (CC BY-NC 4.0).

(C) Copyright E. Barbagelata et al., 2018

Licensee PAGEPress, Italy

Italian Journal of Medicine 2018; 12:171-179

doi:10.4081/itjm.2018.987 of smoking among men worldwide, historically COPD was considered to be a disease that mainly affected elderly men. ${ }^{1}$ However, in recent years, things have changed and now COPD is a disease that affects women, and in many developed countries, COPD has currently become even more prevalent in women than men. ${ }^{2}$ Furthermore there has been also a steady increase in COPD mortality rates in women. For example, in the year 2000, for the first time in the USA, the number of COPD-associated deaths in women has equaled or surpassed that in men, ${ }^{1}$ while in Canada, a longitudinal population study revealed a greater decrease in COPD-related mortality trends in men versus women. ${ }^{3}$ In the European Union from 1994 to 2010 , the mortality rate in men decreased from 90.1 to 61.3 , but in women, these rates were 27.0 in 1994 and 25.15 in $2010 .^{4}$

The increased prevalence of COPD among women is likely attributable to several factors including the increased rates of cigarette smoking observed in women during recent years, exposure to indoor air pollution (biomass) as well as increased occupational exposures since women take on previously maledominated occupational roles related to risk exposure. ${ }^{3,5}$ Furthermore, several studies have suggested that women may have an increased susceptibility to the lung-damaging effects of smoking compared with men. ${ }^{4,6}$

In underdeveloped and developing countries, COPD is still a men's disease and the rate of smoking in women is still less, which is about $10 \%$. However, there have been other noxious sources such as biomass exposure and secondhand smoking that mainly affect women. ${ }^{7}$

These differences between men and women in their susceptibility to COPD risk factors are possibly 
related to biologic and hormonal mechanisms. In addition, there might be clinical differences based on sex. Whilst women are more likely to develop chronic bronchitis, emphysema appears more common among men $;^{8}$ often women complain much dyspnea than men. Exacerbations may result in different outcomes and the treatment adherence may be different according to the sex. ${ }^{8}$ Diagnosis, symptoms, healthrelated quality of life (HRQoL), co-morbidities, management, natural course, disease progression and mortality could all be influenced by sex, as a result of anatomical and physiological differences between the sexes and cultural and sex-related social factors. ${ }^{1,9}$

The changing disease paradigm among genders highlights the need for an improved understanding of how COPD affects men and women differently, and how treatments could be optimized accordingly. Understanding physiological differences as well as differences in COPD susceptibility between men and women is important as gender-related differences could contribute to variations in management and effect of the treatment.

In this review, we present and discuss the relationship between COPD and gender differences based on the current literature.

\section{Gender difference in risk factors}

\section{Lung and airways development and physiology}

Sex hormones affect lung growth and development, airway hyper-responsiveness and detoxification of tobacco smoke. The pubertal switch in asthma from a male-predominant disease to a female-predominant disease may be a manifestation of such effects. Estrogen can induce differentiation and maturation of the lung. It may also be involved in the production of cytokines, triggering a Th2dominant immune response. Growing evidence indicates that estrogen may delay the loss of lung function, with maintenance of alveolar structure and the number of alveolar attachments to small conducting airways, cilia beat and epithelial nitric oxide. ${ }^{10,11}$ Menopause, which is associated with the decline in estrogen and progesterone, is an important cause of accelerated alveolar loss. ${ }^{10}$ In a recent study on biomarkers in COPD, by Torres et al., cytokines such as interleukin 16, pulmonary and activationregulated chemokine and vascular endothelial growth factor were independently associated with female sex. $^{12}$

Sex differences are also manifested in expression of key genes. For example, surfactant production appears earlier in female than in male neonatal lungs. ${ }^{13}$ This earlier appearance of surfactant in female neonatal lungs favors patency of small airways and airspaces and may contribute to their higher airflow rate and lower airway resistance compared to neonatal males. ${ }^{14}$ Consequently neonate males have an elevated risk of developing respiratory distress syndrome (RDS) and dying because of this compared to neonate females. ${ }^{15}$ Female lungs tend to be smaller and weigh less than those of males and, on average, may contain fewer respiratory bronchioles at birth. ${ }^{16}$ The number of alveoli per unit area and alveolar volume does not differ between boys and girls, but boys have larger lungs than girls. ${ }^{16}$ Thus, the total number of alveoli and alveolar surface area are larger for boys than for girls of a given age. Whereas, large airways tend to grow faster than parenchymal tissue in young females, the growth of large airways tends to lag behind that of the parenchyma in young males in a phenomenon known as dysanaptic growth, resulting in relatively narrower airways in young males than in young females. ${ }^{17}$ During childhood and adolescence maturation of the airways and lungs continues and males continue to have larger lungs than females. Considerable experimental animal data support a role for sex hormones in regulating lung development. Androgens and estrogens have been shown to exert inhibitory and stimulatory effects, respectively on lung surfactant production in a variety of species by a mechanism involving alteration of epidermal growth factor and transforming growth factor- $\beta$ (TGF- $\beta$ ) signaling events. ${ }^{18}$ Adult female mice and rats have more and smaller alveoli than males, ${ }^{19}$ thereby providing them with larger alveolar surface area to body mass ratios, whereas adult male mice have larger absolute lung volumes than females but smaller volume to body mass ratios. The formation and maintenance of a full complement of alveoli in females depends on estrogens and has been shown to be mediated in mice by ER $\alpha$ and ER $\beta$. Genetic deletion of ER $\alpha$ or ER $\beta$ decreases the number and increases the size of alveoli in mice, and these changes are more prominent in females than in males. ${ }^{20}$

\section{Race}

About race and gender differences in the effects of smoking on lung function, has been showed that, between 330 COPD patients, Caucasians had less loss of lung function per pack-year smoked than African Americans and men less than women. ${ }^{21}$ Silverman et al. found elevated prevalence of COPD $(71.4 \%)$ in females among the early-onset COPD pro-bands. Female first-degree relatives had significantly lower forced expiratory volume in one second/forced vital capacity $\left(\mathrm{FEV}_{1} / \mathrm{FVC}\right)$, with greater bronchodilator responsiveness. Female first-degree relatives who smoked had significantly greater risk of $\mathrm{FEV}_{1}<40 \%$ (odds ratio: 3.56 ). These results suggest that women may be more susceptible to the development 
of severe COPD. ${ }^{22}$ In the COPD Gene Study, severe early-onset COPD subjects were predominantly female (66\%). ${ }^{23}$ Subsequently, Jordan et al. in their cross-sectional analysis of data from Health Survey for England raised a potential explanation for this controversy. They found that when using the GOLD (Global Initiative for Obstructive Lung Disease), and NICE (National Institute for Health and Clinical Excellence) definitions, women appeared to have a significantly greater susceptibility to COPD for the same level of smoke exposure, but this was not seen when using the lower limit of normal criteria. ${ }^{24}$

\section{Smoking}

The best-known etiological factor for COPD is smoke. While smoking rates in women have largely stabilized in developed countries, the rates continue to increase in developing countries: if effective antitobacco initiatives and action plans are not implemented, the prevalence of women smokers is predicted to rise up to $20 \%$ by 2025 in these countries. This would mean that there will be 532 million women smokers worldwide by $2025.4,25$ Men and women may have differential susceptibility to the lung-damaging effects of cigarette smoking; in a large population study, females appear to have more severe COPD with early-onset disease ( $<60 \mathrm{yr})$ and a greater susceptibility to COPD with lower tobacco exposure. ${ }^{6}$ Several studies have searched the biological background of possible greater susceptibility to cigarette smoke in women: several etiologies are possible. First, women could be genetically more predisposed to smoking-induced lung damage; second, there might be a greater dose-dependent effect in women smokers. Women have smaller airways than men, so this could cause more exposure with a comparatively smaller amount of smoke. ${ }^{4}$ In a recent mouse model, the excess risk of small airways disease in female mice after chronic smoke exposure was found to be associated with increased oxidative stress and transforming growth factor beta (TGF $\beta 1$ ) signaling, and it is related to the effects of female sex hormones. ${ }^{26}$ Third, there may be hormonally mediated differences also in tobacco-smoke metabolism. ${ }^{4}$

Exposure to second-hand smoking is another important risk factor. The relative risk for having COPD from second-hand smoking is 1.31 in China, where second-hand smoking has been extremely prevalent. About $49.2 \%$ of Chinese non-smokers are exposed at home to second-hand smoking: of those, $51.3 \%$ are women and $12.1 \%$ are men.

\section{Asthma/chronic obstructive pulmonary disease overlap syndrome}

Among adults with COPD, between 13\% and 55\% have been reported to also have asthma, termed asthma/COPD overlap syndrome (ACOS), which is characterized by persistent airflow limitation with several features of both asthma and COPD. Some, but not all, studies have reported ACOS to be more common in women; however, no studies have primarily focused on the role of gender in ACOS as compared to asthma or COPD. An Italian study that included an $\mathrm{ACOS}$ group ${ }^{27}$ reported that prevalence of every asthma or COPD was not significantly different by gender.

\section{Infections}

Tracheobronchial infections occurred in similar frequency of exacerbations in both men and women. For females the lapse of time between the onset of symptoms and the admission to hospital was much longer. ${ }^{1,7}$

\section{Occupational and non-occupational exposure}

A significant burden of COPD is attributable to nonsmoking risk factors, such as occupational exposure, traffic and other outdoor pollution, indoor air pollution, second-hand smoke, outdoor and indoor biomass smoke, dietary factors, chronic asthma and tuberculosis. ${ }^{28,29}$ Epidemiologic studies have shown that $5-12 \%$ of subjects with COPD are non-smokers. Biomass smoke contains many harmful pollutants, which can cause acute respiratory infections and chronic respiratory diseases; coal smoke contains sulphur and nitrogen oxides and hydrocarbons that can cause cancer. According to the World Health Organization (WHO), it has been estimated that about 2.4 billion people (about $50 \%$ of world's population) and $90 \%$ of people living in rural areas use biomass fuel as the primary energy source for domestic purposes: ${ }^{30,31}$ women, spending more time indoors for cooking, are more exposed to biomass fuel combustion products than men.

Another less mentioned possible etiologic factor for COPD is malnutrition. An estimated $20-45 \%$ of women of childbearing age in the developing world do not eat the WHO recommended 2250 calories a day. Underweight newborns who are delivered by unhealthy mothers are also at risk. All those factors are mostly related to low socio-economic status associated with poverty, which disproportionately affects women. ${ }^{6}$ Table 1 summarizes the gender differences in risk factors for COPD.

\section{Gender difference in diagnosis}

Health care providers are more likely to diagnose COPD in men than women. This has obviously important implications in the care and outcome of these patients. 
Although women present with COPD symptoms, they are less likely to receive spirometry.,32,33 In a recent study, which involved 3,500 subjects from Spain, $73 \%$ of the patients with spirometric COPD criteria were underdiagnosed, and this percentage was unevenly distributed by sex, being over a quarter times more frequent in women than in men. ${ }^{34}$ Spirometry can reduce the risk of underdiagnosis and gender bias but data show that only $22 \%$ of the physicians request a spirometry. ${ }^{35}$ In a study of 397 COPD subjects (52\% women), self-reported COPD was common among men, and co-diagnosis of COPD with asthma was more common among women $(\mathrm{P}>0.05){ }^{36}$

There may be also a sex disparity in using health resources and patients' perception about their illness and health resource availability. A recent populationbased prevalence study found that women were more likely to report COPD diagnostic delay, difficulty reaching their physician and reported that time spent with their physician was insufficient. ${ }^{37}$ Table 2 highlights gender differences in diagnosis of COPD.

\section{Gender difference in phenotypic manifestations}

There are phenotypic differences between women and men in the expression of COPD, as suggested by several studies. A recent USA study showed that similar numbers of women and men reported dyspnea, but women reported less phlegm and rated their health as poor/very poor. ${ }^{37}$ NHIS data similarly suggest that chronic bronchitis is more common among women, and emphysema is traditionally more common among men, although since 2011 more women in the US have been diagnosed with emphysema than men. ${ }^{38}$ In the European Respiratory Society study on COPD (EUROSCOP study), men and women reported similar symptoms; however men had more wintertime phlegm production; symptoms were only correlated with baseline $\mathrm{FEV}_{1}$ in men but not in women. ${ }^{39}$ Several studies have shown that women have better functional parameters than men, but even correcting for degree of airflow obstruction, women report more anxiety and depression, worse symptoms (more dyspnea and more exacerbations), lower exercise capacity, more airway hyperresponsiveness, and worse HRQoL than men. ${ }^{4}, 40$ Data from the TORCH (Toward a Revolution in COPD Health) study showed that women ( $\mathrm{n}=1481$ ) had higher $\mathrm{FEV}_{1}(47 \%$ vs $44 \%$ predicted), worse St. George's Respiratory Questionnaire, and worse Medical Council Research Score than men $(n=4631)$. After adjusting for differences in baseline factors, the risk of mortality was $16 \%$ higher in men than in women, although this was not statistically significant. Causes of deaths were similar in both sexes; exacerbations were $25 \%$ higher in women. ${ }^{40}$ Recent data from Spain showed that

Table 1. Gender difference in risk factors.

1. Sex hormones affect lung growth and development, airway hyper-responsiveness and detoxification of tobacco smoke. Sex hormones affect lung growth and development, airway hyper-responsiveness and detoxification of tobacco smoke. Estrogen can induce differentiation and maturation of the lung. Menopause, which is associated with the decline in estrogen and progesterone, is an important cause of accelerated alveolar loss

2. Men have less loss of lung function per pack-year smoked than women

3. Men and women may have differential susceptibility to the lung-damaging effects of cigarette smoking; females appear to have more severe chronic obstructive pulmonary disease (COPD) with early-onset disease and a greater susceptibility to COPD with lower tobacco exposure

4. Among adults with COPD, about $30 \%$ have been reported to have also asthma, termed asthma/COPD overlap syndrome (ACOS), which is characterized by persistent airflow limitation with several features of both asthma and COPD. Some studies have reported ACOS to be more common in women

5. Tracheobronchial infections occurred in similar frequency of exacerbations both in men and women. Females had much longer time from the onset of symptoms

6. A significant burden of COPD is attributable to non-smoking risk factors, such as occupational exposure, traffic and other outdoor pollution, indoor air pollution, second-hand smoke, outdoor and indoor biomass smoke, dietary factors, chronic asthma and tuberculosis.

Women, spending more time indoors, are more exposed to biomass fuel combustion products than men

Table 2. Gender difference in diagnosis.

1. Health care providers are more likely to diagnose chronic obstructive pulmonary disease (COPD) in men than women

2. Although women present with COPD symptoms, they are less likely to receive spirometry

3. Self-reported COPD is common among men, and co-diagnosis of COPD with asthma is more common among women 
women patients with COPD were significantly younger, had better pulmonary function tests, smoked less but had worse quality of life measured using the EQ-5D and Airways Questionnaire 20 (AQ20), higher anxiety and depression. ${ }^{41}$ In a very recent study conducted by Gonzalez in 19,260 women and 23,893 men in Quebec, men had significantly worse survival and significantly increased risk of re-hospitalization for COPD. ${ }^{42}$

The risk of death in patients with COPD is often graded with the use of a single physiological variable, $\mathrm{FEV}_{1}$. Recently, in a population of predominantly male patients with COPD a multidimensional evaluation of disease severity and prognosis has been validated: the BODE index (body mass index, degree of airway obstruction, dyspnea and exercise capacity) as a better independent predictor of respiratory and overall mortality than $\mathrm{FEV}_{1} \cdot{ }^{40}$ In 2005 De Torres et al. found that men and women with the same $\mathrm{FEV}_{1} \%$ show differences in the clinical presentation of the disease; they also found significant differences in all the components of the BODE index; the relative weight of each component of the BODE index differs by gender. Women had worse dyspnea, exercise capacity, and nutritional status at an earlier stage of the disease. Perception of disease and nutritional status has a more important role in women with COPD when a multidimensional evaluation of the disease is performed. The BODE index might be particularly useful in assessing COPD severity in women because it takes into account those aspects of the disease most relevant to this population for a given degree of airflow obstruction. ${ }^{43}$

Martinez et al. examined the computed tomography data from the National Emphysema Treatment Trial: women had less emphysema, smaller airways, and thicker airway walls. Women were younger and exhibited lower body mass index (BMI), shorter smoking history, less severe airflow obstruction, lower carbon monoxide diffusion lung capacity and arterial partial oxygen pressure, higher arterial partial carbon dioxide pressure, shorter 6 minute walk distance, and lower maximal wattage during oxygen-supplemented cycle-ergometer. ${ }^{44}$ Recently COPD Gene Study has investigated if sex- specific differences in emphysema persists within different subgroups; i.e., i) different GOLD spirometric severity; ii) early-onset COPD $(<55$ years old); iii) advanced emphysema ( $>25 \%$ emphysema). Compared with females, males had higher emphysema. Females with early-onset COPD, severe emphysema and GOLD grade-IV COPD had similar emphysema as males but markedly fewer pack-years smoking history. ${ }^{45}$

The reasons behind differences in clinical expression of COPD between men and women are likely multifactorial. Patients' response to dyspnea has been affected by their emotional response and interpretation of the dyspneic sensation. Neurobiological studies showed that women had higher intrinsic sensitivity to somatic sensations including dyspnea. Women also demonstrate greater attention to somatic sensations. ${ }^{46}$ Becklake and Kauffmann suggested that societal concepts of athleticism may cause men to report less breathlessness than women; ${ }^{47}$ others have suggested that socio-cultural factors may result in women being less likely to report the production of sputum or phlegm. Some physiologic data suggest that fat-free body mass, which is lower in women with COPD, is related to a lower diffusion capacity and more dyspnea. ${ }^{48}$ In Table 3 are summarized phenotypic differences between women and men in the expression of COPD.

\section{Gender differences in comorbidities}

Sex differences in comorbidities are understudied. Many studies found that women were more likely to have depression, anxiety, fatigue, lower BMI and fatfree mass and more exacerbations than men. ${ }^{9,40,49,50}$ The ECLIPSE (Evaluation of COPD Longitudinally to Identify Predictive Surrogate End-points) study showed that, in females, cardiovascular comorbidity and diabetes mellitus were less prevalent, whereas osteoporosis, inflammatory bowel disease, reflux and depression were more prevalent. ${ }^{50,51}$ In a Spanish study, instead, females had more heart failure, osteoporosis and diabetes mellitus but less comorbidity compared with men (1.8 vs 3.7); the mean

Table 3. Gender difference in phenotypic manifestations.

1. Similar numbers of women and men have reported dyspnea, but women have reported less phlegm and rated their health as poor/very poor

2. Chronic bronchitis is more common among women, and emphysema is traditionally more common among men

3. Exacerbations are higher in women

4. Women at the same disease severity had less emphysema, smaller airways, and thicker airway walls; moreover, they are younger and exhibit lower body mass index, shorter smoking history, less severe airflow obstruction, lower carbon monoxide diffusion lung capacity and arterial partial oxygen pressure, higher arterial partial carbon dioxide pressure, shorter 6-minute walk distance, and lower maximal wattage during oxygen-supplemented cycle-ergometer 
Charlson comorbidity index score was 2.7 and not different between the sexes. ${ }^{52}$ In a Swedish study, men had more lung cancer, ischemic heart disease and renal failure and women had more osteoporosis, hypertension, rheumatoid arthritis, and mental disease.${ }^{53} \mathrm{~A}$ study evaluating sex differences in the prevalence of psychiatric disorders and psychological distress in COPD showed that women had significantly higher anxiety sensitivity and depressive symptoms compared to men, but did not report more limitations in psychological functioning. Women also reported being less confident in their ability to control respiratory symptoms, and more daily physical limitations compared to men, despite having comparable COPD severity, dyspnea scores and exacerbation rates. ${ }^{4,44,54} \mathrm{In}$ another study conducted in Italy, women had more anxiety, depression and dyspnea than men. ${ }^{55}$

There are only a few studies conducted on COPD exacerbation, but there might be differences between women and men. The in-hospital mortality due to COPD exacerbation was higher in men of a crosssectional study utilizing the 1996 Nationwide Inpatient Sample that included 71,130 patients with COPD exacerbations. ${ }^{56}$ Females have more moderate and severe exacerbations, more hospitalization due to exacerbations, and prolonged length of stay for hospitalization. ${ }^{57}$ Probably Table 4 summarizes gender differences in comorbidities of COPD patients.

\section{Gender differences in treatment}

Treatment effects and adverse events are not systematically investigated in women and they may be under-treated.

Most studies of pharmacologic agents for COPD have not been designed to assess treatment in men versus women and most trials have enrolled more males than females. For example, little is known about how differences in lung anatomy and physiology of males and females may affect dosage, delivery, and effectiveness of inhaled medications. Based on current studies, there is minimal known effect of sex on efficacy and adverse events of current therapies. ${ }^{7}$ There may also be sex differences in prescribing habits of providers, as well as compliance with medications between men and women. Dales et al. found that among patients with mild-to-moderate COPD, the proportion of females on respiratory medications was twice that of males; this difference was not seen in severe COPD..$^{33}$

There may also be sex differences in device preferences. Sestini et al. found that men were more prescribed new dry powder inhalers versus metered dose inhalers. ${ }^{58}$ One study found no male/female differences in the efficacy of salmeterol/fluticasone combination therapy on pre-dose $\mathrm{FEV}_{1}$, exacerbation rate, or QoL scores and there were no differences in adverse events. ${ }^{59}$ Instead another study demonstrated that the effects of tiotropium on lung function, symptoms, and QoL were similar in men and women. ${ }^{60}$ Budesonide led to a reduction in phlegm among men but not women in the Euroscop study. ${ }^{39}$ The probability of respiratory deterioration (either symptomatic or exacerbations) when stopping inhaled steroids is higher among women than among men. ${ }^{61}$ A more recent study evaluated the response of indacaterol/glycopyrronium by sex in patients with COPD: the authors observed that improvements in health status, dyspnea rescue medication use were generally larger in women than in men. ${ }^{62}$

Certainly, large and better-designed trials are necessary to determine whether clinically meaningful sex differences exist in the pharmacotherapy of COPD.

\section{Smoking cessation}

Smoking cessation is the only intervention documented to slow lung-function decline. Women are not only more susceptible to adverse effects of tobacco smoking but also, they may have more benefits upon successfully quitting smoking. This was demonstrated in the Lung Health Study that showed that women who remained nonsmokers had an average improvement in their FEV1\% predicted during the first year that was 2.5 times greater than the

Table 4. Gender differences in comorbidities.

1. In females, cardiovascular comorbidity and diabetes mellitus are less prevalent, whereas osteoporosis, inflammatory bowel disease, reflux and depression are more prevalent

2. Men have more lung cancer, ischemic heart disease and renal failure and women more osteoporosis, hypertension, rheumatoid arthritis, and mental disease

3. Women have significantly higher anxiety sensitivity and depressive symptoms compared to men, but do not report more limitations in psychological functioning

4. Females have more moderate and severe exacerbations, more hospitalization due to exacerbations, and prolonged length of stay for hospitalization 
Table 5. Gender differences in treatment.

1. Women are not only more susceptible to adverse effects of tobacco smoking but they may also have more benefits upon successfully quitting smoking

2. Long-term oxygen therapy (LTOT) improves survival among hypoxemic patients with chronic obstructive pulmonary disease, but the impact of sex on LTOT is not clear

3. Multidisciplinary pulmonary rehabilitation program have showed both in men and women similar improvements in health-related quality of life measures; after 18 months, however, continued benefits were seen in men but not in women

4. Pneumococcal vaccination coverage is higher in men than in women and in subject with high education level

improvement seen in their male counterparts. ${ }^{63}$ In a recent study Henoch et al. have shown that only $34 \%$ of currently smoking patients participated in a smoking cessation program and $22 \%$ of them in an educational program with women taking part in more than men. ${ }^{64}$ Older pharmacologic therapy with nicotine replacement was more beneficial among men, whereas the newer agents bupropion and varenicline seem to be equally effective in women and men. ${ }^{46}$ Therefore, although women have more difficulties quitting smoke cigarettes, they may have more benefit if they are successful.

\section{Long-term oxygen therapy}

Long-term oxygen therapy (LTOT) improves survival among hypoxemic patients with COPD, but the impact of sex on LTOT is not clear. In fact, a metaanalysis showed that women on LTOT had a survival advantage over men, ${ }^{65}$ but, Machado et al. reported that survival was significantly worse among women with COPD receiving LTOT. ${ }^{66}$ These discrepancies may be due in part to patient population and analytical approaches, and in part to the criteria for indications to start LTOT.

\section{Pulmonary rehabilitation}

A multidisciplinary pulmonary rehabilitation program should be part of the therapy of all patients with COPD, and should include components of exercise training, nutritional counseling, and patient education. Foy et al. demonstrated that after 3 months of exercise therapy, both men and women reported similar improvements in HRQoL measures; after 18 months, however, continued benefits were seen in men but not in women. ${ }^{67}$ Moreover Nguyen and coll. in a retrospective study observed significant differences between men and women: women with COPD showed a statistically significant improvement with respect to overall quality of life as measured by St. George's Respiratory Questionnaire and showed significant improvement in their depression score, while only men with COPD showed any improvement in their sleep quality measured by the Pittsburgh Sleep Quality Index. ${ }^{68}$

\section{Vaccination}

Influenza and pneumococcal vaccination are recommended in patients with COPD to decrease associated risks at all stages. No correlation was found with age, gender and severity of the disease regarding the coverage rate of both vaccination. ${ }^{69}$ Conversely, pneumococcal coverage in another study was higher in men than in women and in subjects with whitecollar occupation and high education level. ${ }^{70}$ Table 5 shows gender differences in the treatment of COPD.

\section{Conclusions}

The influence of gender on COPD risk and outcomes is due to a complex combination of both genetic/biophysiological factors and environmental/ behavioral factors. Identifying the reasons and mechanisms behind those factors, as well as the sex differences in the pattern of comorbidities, exacerbations, and therapeutic response, may lead to improved therapies and outcomes of COPD's patients.

In our opinion it is necessary that healthcare professionals recognize the gender differences in patients with COPD to develop a more genderoriented approach towards diagnosis and treatment of COPD and to improve assessment, monitoring and treatment of this disease.

\section{References}

1. Kokturk N, Kilic H, Baha A, Lee SD, Jones PW. Sex difference in chronic obstructive lung disease. Does it matter? A concise review. COPD 2016;13:799-806.

2. Chapman KR, Tashkin DP, Pye DJ. Gender bias in the diagnosis of COPD. Chest 2001;119:1691-5.

3. Gershon A, Hwee J, Victor JC, et al. Mortality trends in women and men with COPD in Ontario, Canada, 19962012. Thorax. 2015;70:121-6.

4. Aryal S, Diaz-Guzman E, Mannino DM. COPD and sex differences: an update. Transl Res 2013;162:208-18.

5. Allen SS. Cigarette smoking among women: how can we help? Min Med. 2014;97:41-3.

6. Sorheim IC, Johannessen A, Gulsvik A, et al. Gender differences in COPD: are women more susceptible to 
smoking effects than men? Thorax. 2010;65:480-5.

7. Aryal S, Diaz-Guzman E, Mannino DM. Influence of sex on chronic obstructive pulmonary disease risk and treatment outcomes. Int J COPD 2014;9:1145-54.

8. Ohar J, Fromer L, Donohue JF. Reconsidering sex-based stereotypes of COPD. Prim Care Respir J 2011;20:370-8.

9. Camp PG, Goring SM. Sex and the diagnosis, management, and surveillance of chronic obstructive pulmonary disease. Proc Am Thorac Soc 2007;4:686-91.

10. Kamil F, Pinzon I, Foreman MG. Sex and race factors in early-onset COPD. Curr Opin Pulm Med 2013; 19:140-4.

11. Lou P, Zhu Y, Chen P, et al. Vulnerability of patients with chronic obstructive pulmonary disease according to sex in China. Int J Chron Obstruct Pulmon Dis 2012; 7:825-32.

12. Torres JP, Casanova C, Pinto-Plata V, et al. Sex differences in plasma biomarker levels in a cohort of COPD Patients: A Pilot Study. PLoS One 2011;6:e1602.

13. Fleisher B. Lung profile: sex differences in normal pregnancy. Obstet Gynecol. 1985;66:327-30.

14. Doershuk CF. Specific airway resistance from the perinatal period into adulthood. Alterations in childhood pulmonary disease. Am Rev Respir Dis. 1974;109:452-7.

15. Perelman RH. Discordance between male and female deaths due to the respiratory distress syndrome. Pediatrics 1986;78:238-44.

16. Thurlbeck WM. Postnatal human lung growth. Thorax 1982;37:564-71.

17. Hoffstein V. Relationship between lung volume, maximal expiratory flow, forced expiratory volume in one second, and tracheal area in normal men and women. Am Rev Respir Dis 1986;134:956-61.

18. Carey MA. The impact of sex and sex hormones on lung physiology and disease: lessons from animal studies. Am J Physiol Lung Cell Mol Physiol 2007 [Epub ahead of print].

19. Massaro GD. Sexual dimorphism in the architecture of the lung's gas-exchange region. Proc Natl Acad Sci U S A 1995;92:1105-7.

20. Massaro D, Massaro GD. Estrogen receptor regulation of pulmonary alveolar dimensions: alveolar sexual dimorphism in mice. Am J Physiol Lung Cell Mol Physiol 2006;290:L866-70.

21. Dransfield MT, Davis JJ, Gerald LB, Bailey WC. Racial and sex differences in susceptibility to tobacco smoke among patients with chronic obstructive pulmonary disease. Respir Med 2006;100:1110-6.

22. Silverman EK, Weiss ST, Drazen JM, et al. Sex-related differences in severe, early-onset chronic obstructive pulmonary disease. Am J Respir Crit Care Med 2000; 162:2152-8

23. Foreman MG, Zhang L, Murphy J, et al. Early-onset chronic obstructive pulmonary disease is associated with female sex, maternal factors, and African American race in the COPD Gene Study. Am J Respir Crit Care Med 2011;184:414-20

24. Jordan RE, Miller MR, Lam KH, et al. Sex, susceptibility to smoking and chronic obstructive pulmonary disease: the effect of different diagnostic criteria. Analysis of the Health Survey for England. Thorax 2012;67:600-5.

25. Mackay J, Amos A. Invited review series: tobacco and lung health. Women and tobacco. Respirology 2003; 8:123-30.

26. Tam A, Churg A, Wright JL, et al. Sex differences in airway remodeling in a mouse model of chronic obstructive pulmonary disease. Am J Respir Crit Care Med 2016;193:825-34

27. De Marco R, Pesce G, Marcon A, et al. The coexistence of asthma and chronic obstructive pulmonary disease (COPD): prevalence and risk factors in young, middleaged and elderly people from the general population. PLoS One. 2013;8:e62985.

28. Eisner MD, Anthonisen N, Coultas D, et al. An official American thoracic society public policy statement: novel risk factors and the global burden of chronic obstructive pulmonary disease. Am J Respir Crit Care Med 2010;182:693-718.

29. Vijayan CV. Chronic obstructive pulmonary disease. Indian J Med Res 2013;137:251-69.

30. Zhou Y, Chen R. Risk factors and intervention for chronic obstructive pulmonary disease in China. Respirology 2013;18:4-9.

31. Bruce N, Perez-Padilla R, Albalak R. Indoor air pollution in developing countries: a major environmental and public health challenge. Bull World Health Organ 2000;78:1078-92.

32. Miravitlles M, de la Roza C, Naberan K, et al. Attitude toward the diagnosis of chronic obstructive pulmonary disease in primary care [in Spanish]. Arch Broncopneumol 2006;42:3-8.

33. Dales RE, Mehdizadeh A, Aaron SD, et al. Sex differences in the clinical presentation and management of airflow obstruction. Eur Respir J 2006;28:319-22.

34. Ancochea J, Miravitlles M, Garcia-Rio F, et al. Under diagnosis of chronic obstructive pulmonary disease in women: quantification of the problem, determinants and proposed actions. Arch Bronconeumol 2013;49:223-9.

35. Ben-Zaken Cohen S, Paré PD, Man SF, Sin DD. The growing burden of chronic obstructive pulmonary disease and lung cancer in women examining sex differences in cigarette smoke metabolism. Am J Respir Crit Care Med 2007;176:113-20.

36. Cydulka RK, Rowe BH, Clark S, et al. Sex differences in emergency department patients with chronic obstructive pulmonary disease exacerbation. Acad Emerg Med 2005;12:1173-9.

37. Martinez CH, Raparla S, Plauschinat CA, et al. Sex differences in symptoms and care delivery for chronic obstructive pulmonary disease. J Womens Health 2012; 21:1267-74.

38. Centers for Disease Control and Prevention. National Center for Health Statistics: National Health Interview Survey raw data, 2011. Available from: http://www. cdc.gov/nchs/nhis/nhis 2011 data release.htm

39. Watson L, Vonk JM, Löfdahl CG, et al. Predictors of lung function and its decline in mild to moderate COPD in association with sex: Results from the Euroscop study. Respir Med 2006;100:746-53.

40. Celli B, Vestbo J, Jenkins CR, et al. Sex Differences in mortality and clinical expressions of patients with chronic obstructive pulmonary disease - The TORCH experience. Am J Respir Crit Care Med 2011;183:317-22.

41. Naberan K, Azpeitia A, Cantoni J, Miravitlles M. Impairment of quality of life in women with chronic 
obstructive pulmonary disease. Respir Med 2012;106: 367-73.

42. Gonzalez AV, Suissa S, Pierre Ernst P. Sex differences in survival following hospitalisation for COPD. Thorax 2011;66:38-42.

43. De Torres JP. COPD heterogeneity: gender differences in the multidimensional BODE index. Int $\mathrm{J}$ Chron Obstruct Pulmon Dis 2007;2:151-5.

44. Martinez FJ, Curtis JL, Sciurba F, et al. Sex differences in severe pulmonary emphysema. Am J Respir Crit Care Med 2007;176:243-52.

45. Hardin M, Foreman M, Dransfield MT, et al. Sex-specific features of emphysema among current and former smokers with COPD. Eur Respir J 2016;47:104-12.

46. Han MK, Postma D, Mannino DM, et al. Sex and chronic obstructive pulmonary disease why it matters. Am J Respir Crit Care Med 2007;176:1179-84.

47. Becklake MR, Kauffmann F. Gender differences in airway behavior over the human life span. Thorax 1999; 54:1119-38.

48. Verhage TL, Heijdra Y, Molema J, et al. Associations of muscle depletion with health status. Another gender difference in COPD? Clin Nutr 2011;30:332-8.

49. Tam A, Churg A, Wright JL, et al. Sex differences in airway remodeling in a mouse model of chronic obstructive pulmonary disease. Am J Respir Crit Care Med 2016;193:825-34.

50. Vestbo J, Anderson W, Coxson HO, et al. Evaluation of COPD Longitudinally to Identify Predictive Surrogate End-points (ECLIPSE). Eur Respir J 2008;31:869-73.

51. Agusti A, Calverley PM, Celli B, et al. Characterization of COPD heterogeneity in the ECLIPSE cohort. Respir Res 2010;11:122.

52. Almagro P, LópezGarcía F, Cabrera FJ, et al. Comorbidity and sex-related differences in patients hospitalized for COPD. The ECCO study. Respir Med 2010;104:253-9.

53. Ekström MP, Jogréus C, Ström KE. Comorbidity and sex-related differences in mortality in oxygen-dependent chronic obstructive pulmonary disease. PLoS One 2012; 7:e35806.

54. Laurin C, Lavoie KL, Bacon SL, et al. Sex differences in the prevalence of psychiatric disorders and psychological distress in patients with COPD. Chest 2007; 132:148-55.

55. Di Marco F, Verga M, Reggente M, et al. Anxiety and depression in COPD patients: the roles of sex and disease severity. Respir Med 2006;100:1767-74.

56. Patil SP, Krishnan JA, Lechtzin N, Diette GB. Inhospital mortality following acute exacerbations of chronic obstructive pulmonary disease. Arch Intern Med 2003;163:1180-6.

57. Kilic H, Kokturk N, Sar1 G, Cakir M. Do females behave differently in COPD exacerbations? Int J COPD 2015;10:823-30.

58. Sestini P, Cappiello V, Aliani M, et al. Prescription bias and factors associated with improper use of inhalers. J Aerosol Med 2006;19:127-36.

59. Vestbo J, Soriano JB, Anderson JA, et al. Sex does not influence the response to the combination of salmeterol and fluticasone propionate in COPD. Respir Med 2004; 98:1045-50.

60. O'Donnel DE, Fluge T, Gerken F, et al. Effects of tiotropium on lung hyperinflation, dyspnoea and exercise tolerance in COPD. Eur Respir J 2004;23:832-40.

61. Scherer TR, Hendriks AJ, Chavannes NH, et al. Probability and determinants of relapse after discontinuation of inhaled corticosteroids in patients with COPD treated in general practice. Prim Care Respir J 2004;13:48-55.

62. Tsiligianni I, Mezzi K, Fucile S, et al. Response to indacaterol/glycophyrronium (IND/GLY) by sex in patients with COPD: a pooled analysis from IGNITE Program. COPD 2017; 14:375-81.

63. Bjornson W, Rand C. Gender differences in smoking cessation after 3 years in the Lung Health Study. Am J Public Health 1995;85:223-3.

64. Henoch I, Strang S, Lofdahl CG, Ekberg-Jansson A. Management of COPD, equal treatment across age, gender, social situation? A register study. Intern J COPD 2016;11;2681-90.

65. Crockett AJ, Cranston JM, Moss JR, Alpers JH. Survival on long-term oxygen therapy in chronic airflow limitation: from evidence to outcomes in the routine clinical setting. Intern Med J 2001;31:448-54.

66. Machado MC, Krishnan JA, Buist SA, et al. Sex differences in survival of oxygen-dependent patients with chronic obstructive pulmonary disease. Am J Respir Crit Care Med 2006;174:524-9.

67. Foy CG, Rejeski WJ, Berry MJ, et al. Sex moderates the effects of exercise therapy on health-related quality of life among COPD patients. Chest 2001;119:70-6.

68. Nguyen LP, Beck E, Cayetano K, et al. Differential pulmonary rehabilitation outcomes in patients with and without COPD: role of gender. J Cardiopulm Rehab Prev 2017;5:350-5.

69. Aka Aktürk Ü, Görek Dilektaşlı A, Şengül A, et al. Influenza and pneumonia vaccination rates and factors affecting vaccination among patients with chronic obstructive pulmonary disease. Balkan Med J 2017;34:206-11.

70. Chen $\mathrm{C}-\mathrm{H}, \mathrm{Wu} \mathrm{M}-\mathrm{S}, \mathrm{Wu}$ I-C. Vaccination coverage and associated factorsfor receipt of the 23-valent pneumococcal polysaccharide vaccine in Taiwan. Medicine 2018;97:e9773. 